\title{
A study into the psychosocial determinants of perceived forgetfulness: implications for future interventions
}

Citation for published version (APA):

Mol, M. E. M., Ruiter, R. A. C., Verhey, F. R. J., Dijkstra, J. B., \& Jolles, J. (2008). A study into the psychosocial determinants of perceived forgetfulness: implications for future interventions. Aging \& Mental Health, 12(2), 167-176. https://doi.org/10.1080/13607860801972503

Document status and date:

Published: 01/01/2008

DOI:

10.1080/13607860801972503

Document Version:

Publisher's PDF, also known as Version of record

Please check the document version of this publication:

- A submitted manuscript is the version of the article upon submission and before peer-review. There can be important differences between the submitted version and the official published version of record.

People interested in the research are advised to contact the author for the final version of the publication, or visit the DOI to the publisher's website.

- The final author version and the galley proof are versions of the publication after peer review.

- The final published version features the final layout of the paper including the volume, issue and page numbers.

Link to publication

\footnotetext{
General rights rights.

- You may freely distribute the URL identifying the publication in the public portal. please follow below link for the End User Agreement:

www.umlib.nl/taverne-license

Take down policy

If you believe that this document breaches copyright please contact us at:

repository@maastrichtuniversity.nl

providing details and we will investigate your claim.
}

Copyright and moral rights for the publications made accessible in the public portal are retained by the authors and/or other copyright owners and it is a condition of accessing publications that users recognise and abide by the legal requirements associated with these

- Users may download and print one copy of any publication from the public portal for the purpose of private study or research.

- You may not further distribute the material or use it for any profit-making activity or commercial gain

If the publication is distributed under the terms of Article $25 \mathrm{fa}$ of the Dutch Copyright Act, indicated by the "Taverne" license above, 


\title{
A study into the psychosocial determinants of perceived forgetfulness: implications for future interventions
}

\author{
Martine E.M. Mol ${ }^{\mathrm{a}}$, Robert A.C. Ruiter ${ }^{\mathrm{b}}$, Frans R.J. Verhey ${ }^{\mathrm{a}}$, \\ Jeanette Dijkstra ${ }^{\mathrm{a}}$ and Jelle Jolles ${ }^{\mathrm{a} *}$ \\ ${ }^{a}$ Department of Psychiatry and Neuropsychology, European Graduate School of Neuroscience \\ (Euron), Maastricht University, The Netherlands, ${ }^{b}$ Department of Work \\ and Social Psychology, Maastricht University, The Netherlands
}

(Received 1 November 2006; final version received 25 April 2007)

\begin{abstract}
Many healthy individuals perceive themselves as forgetful and are interested in interventions to decrease their worries and increase their memory functioning. Educational interventions can be more effective when determinants are targeted that are known to predict perceived forgetfulness. In the present study, first, a broad range of determinants was selected from the literature and from experiences in clinical settings and, second, the most important determinants among the selected ones were identified with multivariate regression analyses. The study had a cross-sectional design. A sample of 300 healthy participants aged over 54 years filled in a self-report questionnaire. Findings indicated that low memory self-efficacy, high memory-related anxiety, negative attitude and high subjective norm (e.g. anticipating negative evaluations by important others) were the most important correlates of perceived forgetfulness. It is argued that future interventions should focus on the specified determinants to improve programme effectiveness in reducing subjective memory complaints.
\end{abstract}

Keywords: forgetfulness; determinants; memory; interventions

\section{Introduction}

Memory complaints, or perceived forgetfulness, reflect perceived memory failures and are common among older adults (Jonker, Geerlings, \& Schmand, 2000; Ponds, Commissaris, \& Jolles, 1997). In the Maastricht Aging Study, the prevalence of perceived forgetfulness was approximately $41 \%$ among individuals aged between 55 and 65 years and $52 \%$ among individuals aged between 79 and 85 years (Ponds et al., 1997). In another sample with individuals aged 65 years and older, the proportion of forgetful people was more than 50\% (Blazer, Hays, Fillenbaum, \& Gold, 1997). Several studies have shown an association between subjective memory complaints and cognitive decline (Geerlings, Jonker, Bouter, Ader, \& Schmand, 1999; Schmand, Jonker, Geerlings, \& Lindeboom, 1997). But even though many other studies suggested that subjective memory complaints are not directly associated with cognitive decline (Blazer et al., 1997; Jorm et al., 1997; Mol, van Boxtel, Willems, \& Jolles, 2006), many individuals still experience hindrance and worries from this perceived forgetfulness in daily life (Commissaris, Ponds, \& Jolles, 1998).

A small proportion of people who perceive themselves forgetful are interested in memory training or other educational activities to decrease their worries and increase memory functioning (Commissaris et al., 1998). Most of these programmes aim to improve objective memory functioning, for example by training verbal episodic memory, information processing speed (Ball et al., 2002) or by remembering names (Schmidt, Dijkstra, Berg, \& Deelman, 1999). Many of these programs have not yet been proven to be effective. However, these programmes are not always effective in reducing subjective memory complaints. A study by Rasmusson, Rebok, Bylsma and Brandt (1999) found that older adults who received memory training showed no change in selfreports on memory functioning. Floyd and Scogin (1997) concluded in their meta-analysis that memory training led only to minimal reductions in subjective memory complaints. Many other programs have been tried, but not yet been proven to be effective (West, Welch, \& Yassuda, 2000).

To improve health issues, such as perceived forgetfulness, it is important to get more insight in the problem that is experienced by the individual. A possible way to understand and influence problems is by gaining insight into the factors, or determinants, that influence problems and by identifying the ones that significantly enforce or hinder health issues. Such a determinant analysis is an important step in designing health interventions according to systematic health promotion planning models, such as Intervention Mapping (Bartholomew, Parcel, Kok, \& Gottlieb, 2006) and the PRECEDE-PROCEED planning model (Green \& Kreuter, 2005). These models describe the development process of health promotion interventions development in a series of steps. Studying determinants of the problem is a designated part within the first step of conducting 
a needs assessment. Overall, by aiming interventions at determinants that are known to be correlated to the identified problem, educational interventions can be more effective (Bartholomew et al., 2006; Green \& Kreuter, 2005).

Yet, an overview of important psychosocial, psychiatric and behavioural determinants related to perceived forgetfulness is lacking and no research has been done to determine the most essential correlates of perceived forgetfulness. The present study, therefore, aimed to provide future interventions with relevant target variables by performing a determinant analysis of perceived forgetfulness.

First, the databases of Pubmed and PsychInfo were searched for relevant literature to identify the most important psychological and psychiatric variables that are associated with perceived forgetfulness. The following determinants were identified and used in the present study. A study by Hultsch, Hertzog, Dixon and Davidson (1988) identified four dimensions of meta-memory that are related to perceived forgetfulness. These dimensions encompass different aspects of subjective memory, that is: 'memory knowledge' (defined as factual knowledge about memory tasks), 'memory monitoring' (i.e. selfknowledge about ones capacity), 'memory self-efficacy' (i.e. beliefs about memory abilities and strengths) and 'memory-related anxiety' (i.e. affective state generated by memory-demanding situations). The fear of dementia is also found to be an important factor associated with subjective forgetfulness (Commissaris et al., 1996), as well as symptoms of depression (Comijs, Deeg, Dik, Twisk, \& Jonker, 2002; Commissaris et al., 1998; Jonker et al., 2000) and, therefore, they were also included in the study.

Second, experiences in memory clinics suggest that two types of behaviour are related to perceived forgetfulness. These are, on the one hand, performing a high level of effort in using ones memory and, on the other hand, performing a low level of effort in using ones memory. When someone puts high levels of effort into using his memory, for example by continuously learning large grocery lists by heart or by trying to remember all topics of the eight o'clock news, worrisome thoughts about failing the task might interfere with the attention needed for such a difficult task. This reduces the cognitive resources available for task-processing activities (Eysenck \& Calvo, 1992) and diminishes the ultimate performance on the task. As a consequence, perceived forgetfulness can be experienced. On the other hand, when only little effort is put into remembering things, for example by avoiding a party where you would have to remember the names of the guests, it will lead to inaction of using ones memory. This reduced memory use results in lesser recall and recognition, which can also cause perceived forgetfulness. So, performing either much effort or little effort in the use of one's memory might generate perceived forgetfulness. Both types of behaviour are therefore included as determinants in the present study.

Behaviour is thus believed to be an important determinant of perceived forgetfulness, at least in clinical settings. Because educational interventions typically target behaviour indirectly by influencing psychosocial determinants of behaviour (Bartholomew et al., 2006), several of these determinants of behaviour are also included in the present study. These determinants are derived from the Theory of Planned Behaviour (Ajzen, 1991), which is the most influential explanatory model of behaviour. This model assumes that behaviour is mainly explained by the motivation to perform the behaviour (intention), which in turn is determined by three determinants: attitude, subjective norm and perceived behavioural control (Ajzen, 1991; Norman \& Conner, 2005). 'Attitude' represents a person's overall evaluation of the proposed behaviour. In the context of the present study, attitude refers to a person's evaluation of their memory functioning. 'Subjective norm' reflects beliefs about whether significant others approve of behaviour. In the present study, subjective norms reflect subjective beliefs about how significant others will approve or disapprove of subjective memory complaints. 'Perceived behaviour control' indexes the degree to which people think they can control whether or not they are able to undertake a specific behaviour (Ajzen, 1991). Perceived behaviour control is considered as a similar construct as self-efficacy (Ajzen, 1998; Bandura, 1998). Because memory self-efficacy was already included as a determinant in the study, no extra variable of perceived behaviour control was composed. Furthermore, based on previous literature about the importance of social influence on health behaviour (De Vries, Backbier, Kok, \& Dijkstra, 1995), we included two additional social influence components in the present study. That is, perceived social support, which represents beliefs about how the individual perceives social support to improve subjective memory complaints, and referring to beliefs about how the society reflects on perceived forgetfulness.

In sum, interventions to reduce perceived forgetfulness can be improved when they target determinants that are highly correlated to subjective feelings of perceived forgetfulness. Therefore, the present study aims to establish the relation between the selected determinants and perceived forgetfulness and to identify the determinant(s) with the most predictive value. The following determinants were found to be related to perceived forgetfulness and therefore included in the present study: memory knowledge, memory monitoring, memory selfefficacy, memory-related anxiety, fear of dementia, symptoms of depression, behaviour leading to perceived forgetfulness (much effort and little effort), attitude, social norm, social support and societal beliefs. 


\section{Methods}

\section{Participants and procedure}

The study population consisted of individuals who were members of the Catholic Society for Older People (Katholieke Bond voor Ouderen). This is a widely supported society in the Netherlands consisting of more than 282,000 community citizens aged over 50 years. A priori power analyses (Buchner, Faul, \& Erdfelder, 1992) for the backward logistic regression using a medium effect size of 0.15 (Cohen, 1988), an alpha level of 0.05 and a power of 0.99 indicated a required sample size of 257 participants. We anticipated non-response and incomplete questionnaires and, therefore, invited 1000 participants living in the south of the Netherlands for participation in the study. Three departments of the society were randomly selected and its full population received a letter and questionnaire. This was sent to them by regular mail to invite them to participate in the study. Participants could indicate their willingness to participate in the study by completing the questionnaire and returning it in a prepaid envelope. In total, 360 participants returned the questionnaire. Disease history was asked in the questionnaire. Two individuals who reported cerebrovascular disease were excluded from the study. In addition, 58 participants were excluded because they returned incomplete questionnaires (more than 20\% missing items per scale). This resulted in a total study sample of 300 participants with a mean age of 72 years $(\mathrm{SD}=7.5$, range 53-94) and 59\% being female. The mean level of education was 3.8 $(\mathrm{SD}=1.8)$, measured on a 8 -point scale, ranging from (1) primary education, (2) lower vocational education, (3) intermediate secondary education, (4) intermediate vocational education, (5) higher secondary education, (6) higher vocational education, (7) higher professional education to (8) university education (De Bie, 1987).

\section{Measures}

Each determinant was measured with a scale consisting of several items. Five variables (behaviour leading to perceived forgetfulness, attitude, social norm, social support, societal beliefs) were measured with newly developed scales. We based the structure of these scales on previous research where similar constructs were measured (Dreezens, Martijn, Tenbult, Kok, \& de Vries, 2005; Lemmens et al., 2005). The internal consistency (reliability) of the constructed scales was determined with Cronbach's alpha $(\alpha)$ or in case of scales with only two items with Pearson's correlations (r). The respondent's mean scale score replaced missing values when participants had less than $20 \%$ missing items on a scale. Scales were calculated by averaging the scores on the related items. The scores were coded so that higher scores indicate a higher value of the determinant.

\section{Perceived forgetfulness}

Perceived forgetfulness was rated with the question 'Do you consider yourself to be forgetful?' Response options were yes or no. This single question has previously been successfully used to determine subjective memory complaints (Bassett \& Folstein, 1993; Commissaris et al., 1998; Mol et al., 2006).

\section{Behaviour leading to perceived forgetfulness}

Behaviour was divided into two behavioural determinants, each measured with two items. The first determinant was performing little effort to use one's memory ('little effort': i.e. 'Did you ever avoid someone, because you didn't remember his or her name?', 'Have you ever performed less effort to remember something?', on a scale from $1=$ never to $5=$ always; $r=0.42$ ). The other determinant was performing much effort in using one's memory ('much effort': 'Did you ever excessively focus on your memory?', 'Have you ever performed too much effort in using your memory?', on a scale from $1=$ never to $5=$ always; $r=0.21$ ).

\section{Fear of dementia}

Fear of dementia was measured by two items (i.e. 'Are you worried to become demented?', 'Are you afraid of becoming demented?', on a scale from $1=$ not at all to $5=$ very much; $r=0.69$ ).

\section{Symptoms of depression}

Symptoms of depression were measured by a subscale of the Symptom Checklist (SCL-90 [Dutch version]; Arrindell \& Ettema, 1986; Derogatis, 1977). The SCL90 is a multidimensional self-report inventory of psychopathology, measured with 16 statements. Examples are: 'To what degree where you troubled by feeling low in energy?', 'To what degree where you troubled by feeling lonely?' $(1=$ not at all, $5=$ very badly; $\alpha=0.92$ ).

\section{Memory related-anxiety}

Memory-related anxiety was measured by the subscale Anxiety of the Abridged Dutch Metamemory in Adulthood Questionnaire (MIA: (Dixon, Hultsch, \& Herzog, 1988; Ponds \& Jolles, 1996). Participants were asked to rate 12 statements, reflecting feelings of anxiety and stress about one's memory function (e.g. 'I get anxious when I am asked to remember something', 'I find it harder to remember things when I am upset', on a scale from $1=$ disagree strongly to $5=$ agree strongly; $\alpha=0.88$ ).

\section{Memory self-efficacy}

The MIA was also used to measure memory selfefficacy. Memory self-efficacy, which consists of the mean of the subscales Anxiety (feelings of stress and 
anxiety related to memory performance, 12 items), Change (perceived change in memory function, 10 items) and Capacity (beliefs about personal memory capacity, 10 items), is thought to reflect beliefs about personal competence in various memory situations (Herzog, Hultsch, \& Dixon, 1989). Examples are 'The older I get the harder it is to remember clearly', 'My memory for phone numbers will decline as I get older' $(1=$ disagree strongly, $5=$ agree strongly; $\alpha=0.94$ ).

\section{Memory monitoring}

Memory monitoring was measured by the subscale Capacity of the MIA. Participants were asked to rate 10 statements, reflecting self-knowledge about ones capacity (e.g. 'I am good at remembering birthdays', 'I have no trouble remembering lyrics of songs', on a scale from $1=$ disagree strongly to $5=$ agree strongly; $\alpha=0.91)$.

\section{Attitude}

The attitude towards one's memory was determined with two items (i.e. 'When I think about my memory, my first impression is ..., The feeling I have about my memory is..., on a scale from $1=$ very negative to $5=$ very positive; $r=0.89$ ).

\section{Social norm}

Four items measured the social norm regarding the use of one's memory (e.g. 'Most people important to me think I should not avoid situations were I have to remember things', 'Most people important to me think that I should perform more effort to remember things', 'Most people important to me think I have too high standards for my memory', 'Most people important to me think I should not focus too much on my memory', ranging from $1=$ surely not to $5=$ surely yes; $\alpha=0.76$ ).

\section{Social support}

Four items measured the social support regarding the use of one's memory (e.g. 'Most people important to me encouraged me to perform more effort in using my memory', 'Most people important to me encouraged me to have conversations where I have to remember things', 'Most people important to me encouraged me focus less on my memory' and 'Most people important to me encouraged me to have less high standards for my memory', on a scale from $1=$ surely not to $5=$ surely yes; $\alpha=0.73$ ).

\section{Societal beliefs}

Societal belief was assessed by one item (i.e. 'Perceived forgetfulness is accepted in our society' with the scale ranging from $1=$ disagree strongly to $5=$ agree strongly).

\section{Knowledge}

Knowledge about memory and aging was measured with six items (e.g. 'For older people, education, occupation and verbal skill tend to have little influence on their memory'). Response options were 'yes', 'no' or 'don't know'. The 'don't know' option was added to reduce the likelihood of random guessing and make the questionnaire more sensitive (Cherry, Brigman, Hawley, \& Reese, 2003). Correct responses were scored 1 , all other responses scored 0 , providing a range of total scores between 0 and 6 . The variable knowledge was the total score of correct answers $(\alpha=0.38)$.

To control for demographic characteristics, the factors age, sex and education were also included in the study.

\section{Statistical analyses}

The data was analysed using the statistical software SPSS version 11 program series for Apple Macintosh. Mean scores were calculated to describe each determinant. Pearson's correlations and Spearman's correlations were calculated to establish the correlations between the determinants at an ordinal level and between the ordinal determinants and dichotomous determinants, respectively. A backward logistic regression procedure was used to determine the contribution of each determinant to the prediction of perceived forgetfulness. No previous hypothesis was present with respect to the order of importance of the determinants, so the determinants were entered in the model without specific sequence. The significance level was set at $\alpha=0.05$.

\section{Results \\ Relation between determinants and perceived forgetfulness}

Approximately $48 \%$ of the participants considered themselves as forgetful. Table 1 presents the means, standard deviations and the correlations for all variables. In general, participants had few symptoms of depression, fear of dementia and scored low on the perceived social support and subjective norm. Perceived forgetfulness was significantly correlated with 9 of the 15 determinants, namely attitude $(r=-0.552)$, memory self-efficacy $(r=-0.548)$, memory monitoring $(r=-0.483)$, memory-related anxiety $(r=0.384)$, subjective norm $(r=0.351)$, fear of dementia $(r=0.332)$, social support $(r=0.297)$, symptoms of depression $(r=0.254)$ and behaviour 'little effort' $(r=0.193)$.

\section{Correlates of perceived forgetfulness}

The logistic regression on perceived forgetfulness is presented in Table 2. The significant predictors of 


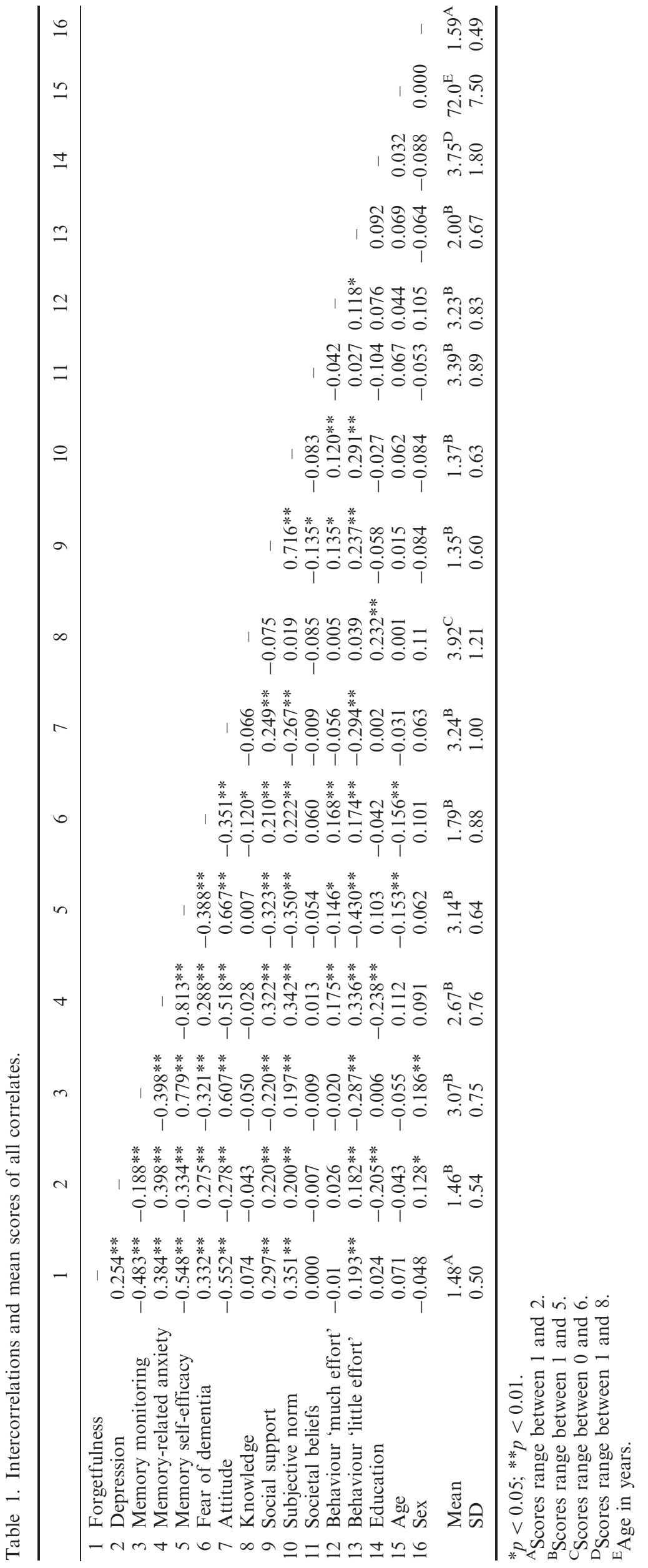




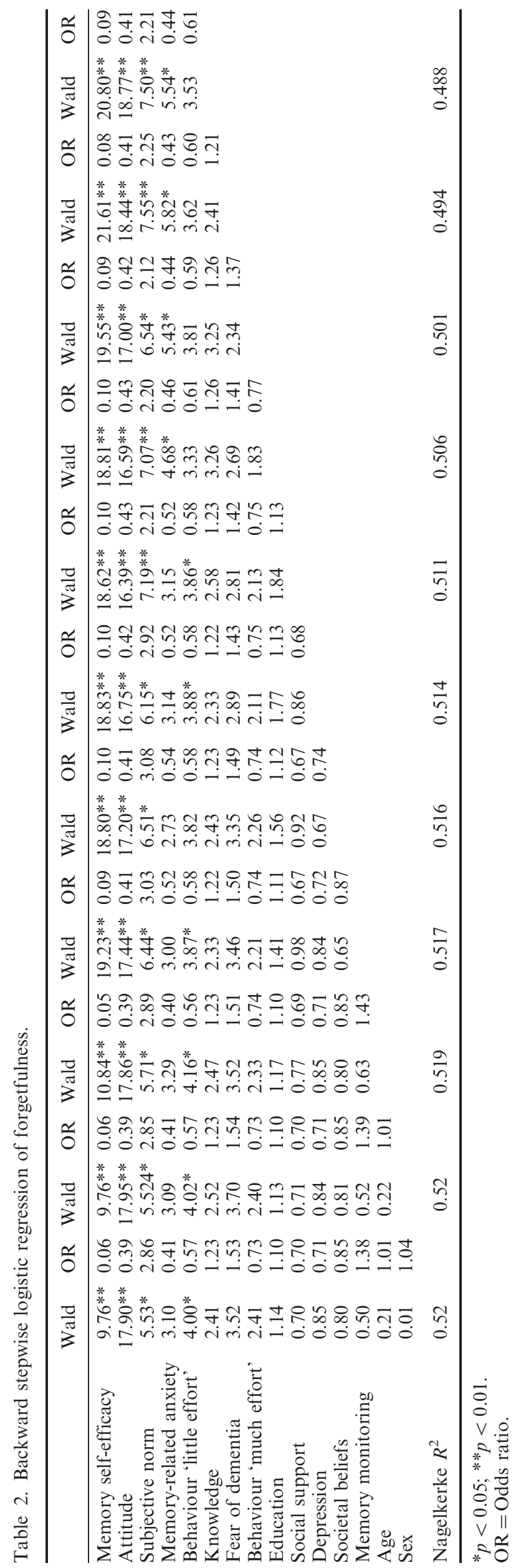


perceived forgetfulness were a low memory selfefficacy (i.e. beliefs about memory abilities and strength), negative attitude (i.e. evaluation of one's memory functioning), high memory-related anxiety (i.e. affective state, generated by memory demanding situations) and high social norm (i.e. anticipating negative evaluations by important others). The determinant 'performing little effort' is still present in the final model, but is not significant. A suppressor-effect (Darlington, 1968; Friedman \& Wall, 2005) was found between memory self-efficacy and anxiety. This is noticeable in the logistic regression, where anxiety has a negative beta weight (i.e. odds ratio below one) despite the fact that the correlation between anxiety and perceived forgetfulness is positive. Because anxiety and memory self-efficacy are correlated, memory selfefficacy consumes a part of the explained variance of anxiety in the regression, resulting in a negative beta weight. When performing a logistic regression without memory self-efficacy, the beta weight of anxiety is in the expected direction. Therefore, the relation between anxiety and perceived forgetfulness is interpreted as a positive relation.

\section{Discussion}

To improve the effectiveness of interventions for individuals with subjective memory complaints, interventions should be targeted at determinants that predict perceived forgetfulness. This study showed that low memory self-efficacy, high memory-related anxiety, negative attitude and high social norm were correlates of perceived forgetfulness.

An important correlate of perceived forgetfulness is memory self-efficacy. Memory-self-efficacy reflects the degree of confidence one has in the ability to mobilize skills for a task (Bandura, 1977, 1989; Hultsch et al., 1988). Poor memory-self-efficacy reflects self-doubt and low self-esteem rather than lack of skills. Besides the influence of memory self-efficacy on subjective memory complaints, memory self-efficacy has also been an important predictor of diminished objective cognitive performance (Valentijn et al., 2006). So, memory self-efficacy is of great importance in predicting the use of ones memory.

Another significant correlate of perceived forgetfulness is memory-related anxiety. Memoryrelated anxiety reflects experienced arousal when forgetting things and perceived tension when using one's memory. The relation between memory-related anxiety and subjective memory complaints was previously studied by Ponds and Jolles (1996), who found that young (age 24-51 years) as well older (age 54-86 years) forgetful participants reported higher memory-related anxiety than non-forgetful participants. Several other studies investigated symptoms of anxiety in relation to memory complaints and found a correlation between severity of subjective memory complaints and anxious symptomatology
(Derouesné et al., 1989; Jorm, Christensen, Korten, Jacomb, \& Henderson, 2001). The findings of the present study contribute to these studies by identifying memory-related anxiety as an important factor in perceived forgetfulness.

Furthermore, attitude towards one's memory was found to be significantly related to perceived forgetfulness, while controlling for other variables. Attitude is defined as a positive or negative evaluation of entity, but can include more specific psychosocial constructs, such as beliefs, outcome expectations, assessment of advantages and disadvantages, self-evaluation and motivation to act (Eagly \& Chaiken, 1993). So, when people perceive themselves forgetful, negative beliefs and evaluations about their memory functioning come to mind. This might possibly be due to negative experiences in the past, for example repeatedly forgetting things, such as keys or names. To our knowledge, it is the first time that the importance of attitude is highlighted with regard to predicting perceived forgetfulness.

Subjective norm is another important correlate of perceived forgetfulness. The subjective norm reflects beliefs about how others will approve or disapprove of subjective memory complaints or perceived memory failure. Apparently, when someone thinks that others will disapprove of their memory failures, it will result in higher perceived expectations, which can lead to perceived failure and, thus, to subjective memory complaints. For example, when you forget your keys, you think your friends will say that you are thoughtless and careless. The next time, you will be extra careful in taking your keys with you. But then you forget your wallet. You think that your friends will say you have failed again to take your belongings with you. When this happens several times, you might think your friends are right and you perceive yourself to be forgetful.

It is interesting to note that behaviours leading to perceived forgetfulness, such as performing much effort and performing little effort, were not important correlates of perceived forgetfulness. The determinant 'performing little effort' was in the final model, but was not significant. This indicates that performing little effort might influence perceived forgetfulness, but is not a very important correlate. Apparently, perceiving oneself as forgetful differs from the behaviour that leads to forgetting things. According to Cromwell (1994), perceived forgetfulness can be seen as a social label that is applied to oneself when acceptable standards for remembering are not met. In this view, labelling oneself forgetful is a personal response to the interaction between one's forgetting and one's social world (Cromwell, 1994). This notion is supported in the present study. Perceiving oneself as forgetful was not solely determined by the behaviour leading to perceived forgetfulness, it was also determined by the experienced subjective norm, which was an important correlate of perceived forgetfulness. In the present 
study, the subjective norm was even a stronger factor than the behaviour leading to perceived forgetfulness.

The findings in this study have several implications for future interventions. A focus of future interventions could be the experienced anxiety and the perceived tension when using one's memory. Furthermore, individuals with perceived forgetfulness experience that their relatives disapprove of their memory complaints. By aiming the intervention at building skills to recognise and resist experienced social pressure (Bartholomew et al., 2006), individuals might cope better with the social influence from others. Also, individuals with subjective memory complaints have a negative attitude about their memory. One of the most widely-used intervention methods for attitude change is the presentation of arguments in a persuasive message (McGuire, 1985), for example by stating that memory complaints are very common and are experienced by more than $50 \%$ of the older population. Another focus of future interventions could be on memory self-efficacy. Poor memory-self-efficacy rather reflects self-doubt and low self-esteem than lack of skills. By enlarging self-esteem in individuals with perceived forgetfulness, better performance and less memory complaints might be accomplished (Baumeister, 1998). This might be achieved by positively reinforcing individuals after remembering and recalling things. Overall, it is preferred that all determinants are addressed in a comprehensive intervention programme to achieve the best possible results (Bartholomew et al., 2006).

Our study has also some methodological considerations and implications for future research. Due to the cross-sectional design of the study, we were not able to determine a causal relation between the determinants and perceived forgetfulness. Future research should aim at performing longitudinal or experimental studies to elaborate on the causal relations. Also, experimental evaluations targeting the determinants highlighted in the present study are required to establish whether our implications can be translated into effective interventions to decrease the subjective memory complaints. Another possible limitation of the current study involved the participants' selection. The sample was not randomly selected, which might have biased the results. Furthermore, it may be that there are other psychosocial factors, not examined in this study, that would be important as well.

Furthermore, the present study did not confirm the relation between perceived forgetfulness and behaviour that is observed in clinical settings. The items measuring the behaviour leading to perceived forgetfulness were newly developed items. Possibly, the items were too abstract and did not match the perceptions of the participant's behaviour leading to perceived forgetfulness. Future studies should also examine the validity of the items. Furthermore, in some instances the reliability scores were quite low, which might also have affected the results. Future studies should re-evaluate the behaviour leading to perceived forgetfulness and investigate whether aspects of the behaviour were missed or not determined correctly.

In conclusion, the findings of the current study, based on 300 participants aged between 53 and 94 years, indicate that the most important determinants of perceived forgetfulness are memory self-efficacy, memory-related anxiety, attitude and subjective norm. The results of the present study give a base for further theory- and hypotheses-guided studies with the aim of systematically testing relevant determinants of perceived forgetfulness. Focusing future interventions on the specific determinants might improve effectiveness of interventions for individuals with perceived forgetfulness.

\section{References}

Ajzen, I. (1991). The theory of planned behaviour. Organizational Behavior and Human Decision Processes, 50, 179-211.

Ajzen, I. (1998). Models of human social behavior and their application to health psychology. Psychology and Health, 13, 735-739.

Arrindell, W.A., \& Ettema, J.H.M. (1986). Scl-90. Manual for a multidimensional indicator of psychopathology [handleiding bij een multidimensionele psychopathologie-indicator]. Lisse, the Netherlands: Swets \& Zeitlinger BV.

Ball, K., Berch, D.B., Helmers, K.F., Jobe, J.B., Leveck, M.D., \& Marsiske, M. (2002). Effects of cognitive training interventions with older adults. Journal of the American Medical Association, 288(18), 2271-2281.

Bandura, A. (1977). Self-efficacy: Towards a unifying theory of behavioral change. Psychology Review, 84, 191-215.

Bandura, A. (1989). Regulation of cognitive processes through perceived self-efficacy. Developmental Psychology, 25, 729-735.

Bandura, A. (1998). Health promotion from the perspective of social cognitive theory. Psychology and Health, 13, 623-649.

Bartholomew, L.K., Parcel, G.S., Kok, G., \& Gottlieb, N.H. (2006). Planning health promotion programs: An intervention mapping approach. San Francisco, CA: Jossey-Bass.

Bassett, S.S., \& Folstein, M.F. (1993). Memory complaint, memory performance and psychiatric diagnosis: A community study. Journal of Geriatric Psychiatry and Neurology, 6(2), 105-111.

Baumeister, R. F. (1998). The self. In D. T. Gilbert, S. Fiske \& G. Lindzey (Eds.), The handbook of social psychology, (Vol. 1, 4th ed., pp. 680-740). New York: McGraw-Hill.

Blazer, D.G., Hays, J.C., Fillenbaum, G.G., \& Gold, D.T. (1997). Memory complaint as a predictor of cognitive decline: A comparison of African American and white elders. Journal of Aging and Health, 9(2), 171-184.

Buchner, A., Faul, F., \& Erdfelder, E. (1992). Gpower: A priori-, post hoc-, and compromise power analyses for the Macintosh. Bonn, Germany: Bonn University, version 2.1.

Cherry, K.E., Brigman, S., Hawley, K.S., \& Reese, C.M. (2003). The knowledge of memory aging questionnaire: Effects of adding a 'don't know' response option. Educational Gerontology, 29, 427-446. 
Cohen, J. (1988). edn. Statistical power analyses for the behavioral sciences (2nd ed.). Hillsdale, NJ: Lawrence Erlbaum.

Comijs, H.C., Deeg, D.J.H., Dik, M.G., Twisk, J.W.R., \& Jonker, C. (2002). Memory complaints: The association with psycho-affective and health problems and the role of personality characteristics. A 6-year follow-up study. Journal of Affective Disorders, 72, 157-165.

Commissaris, C.J.A.M., Jolles, J., Verhey, F.R.J., Ponds, R.W.H.M., Damoiseaux, V., \& Kok, G. (1996). Forgetfulness or dementia? Who is worried and why? European Journal of Public Health, 6, 297-299.

Commissaris, C.J.A.M., Ponds, R.W.H.M., \& Jolles, J. (1998). Subjective forgetfulness in a normal Dutch population: Possibilities for health education and other interventions. Patient Education and Counseling, 34, 25-32.

Cromwell, S.L. (1994). The subjective experience of forgetfulness among elders. Qualitative health research, 4(4), 444-462.

Darlington, R.B. (1968). Multiple regression in psychological research and practice. Psychological Bulletin, 69, 161-182.

De Bie, S. E. (1987). Standaardvragen 1987: Voorstellen voor uniformering van vraagstellingen naar achtergrondkenmerken en interviews [Standard questions 1987: Proposal for uniformisation of questions regarding background variables and interview]. (2nd ed.). Leiden, The Netherlands: Leiden University Press.

De Vries, H., Backbier, E., Kok, G., \& Dijkstra, M. (1995). The impact of social influences in the context of attitude, self-efficacy, intention and previous behaviour as predictors of smoking onset. Journal of Applied Social Psychology, 25, 237-257.

Derogatis, L.R. (1977). Scl-90: Administration, scoring and procedures manual-i for the $R$ (evised) version. Baltimore, MD: John Hopkins School of Medicine, Clinical Psychometrics Research unit.

Derouesné, C., Alperovitch, A., Arvay, N., Migeon, P., Moulin, F., Vollant, M., et al. (1989). Memory complaints in the elderly: A study of 367 community-dwelling individuals from 50 to 80 years old. Archives of Gerontology and Geriatrics, 1 (Suppl.), S151-S163.

Dixon, R.A., Hultsch, D.F., \& Herzog, C. (1988). The metamemory in adulthood (mia) questionaire. Psychopharmacology Bulletin, 24, 671-688.

Dreezens, E., Martijn, C., Tenbult, P., Kok, G., \& de Vries, N.K. (2005). Food and the relation between values and attitude characteristics. Appetite, 45(1), 40-46.

Eagly, A.H., \& Chaiken, S. (1993). The psychology of attitudes. Fox Worth, TX: Harcourt Brace Jovanovich.

Eysenck, M.W., \& Calvo, M.G. (1992). Anxiety and performance: The processing efficiency theory. Cognition and Emotion, 6(6), 409-434.

Floyd, M., \& Scogin, F. (1997). Effects of memory training on the subjective memory functioning and mental health of older adults: A meta-analysis. Psychology and Aging, 12, 150-161.

Friedman, L., \& Wall, M. (2005). Graphical views of suppression and multicollinearity in multiple linear regression. American Statistician, 59(2), 127-136.

Geerlings, M.I., Jonker, C., Bouter, L.M., Ader, H.J., \& Schmand, B. (1999). Association between memory complaints and incident Alzheimer's disease in elderly people with normal baseline cognition. American Journal of Psychiatry, 156, 531-537.
Green, L. W., \& Kreuter, M. W. (2005). Health program planning: An educational and ecological approach (4th ed.). NY: McGraw-Hill Higher Education.

Herzog, C., Hultsch, D.F., \& Dixon, R.A. (1989). Evidence for the convergent validity of two selfreport metamemory questionnaires. Developmental Psychology, 25(5), 687-700.

Hultsch, D.F., Hertzog, C., Dixon, R.A., \& Davidson, H. (1988). Memory self-knowledge and self-efficacy in the aged. In N. L. Lowe, \& C. J. Brainerd (Eds.), Cognitive development in adulthood: Progress in cognitive developmental research (pp. 65-92). New York: Springer-Verlag.

Jonker, C., Geerlings, M.I., \& Schmand, B. (2000). Are memory complains predictive for dementia? A review of clinical and population-based studies. International Journal of Geriatric Psychiatry, 15, 983-991.

Jorm, A.F., Christensen, H., Korten, A.E., Henderson, A.S., Jacomb, P.A., \& Mackinnon, A. (1997). Do cognitive complaints either predict future cognitive decline or reflect past cognitive decline? A longitudinal study of an elderly community sample. Psychological Medicine, 27, 91-98.

Jorm, A.F., Christensen, H., Korten, A.E., Jacomb, P.A., \& Henderson, A.S. (2001). Memory complaints as a precursor of memory impairment in older people: A longitudinal analysis over 7-8 years. Psychological Medicine, 31(3), 441-449.

Lemmens, K.P., Abraham, C., Hoekstra, T., Ruiter, R.A., De Kort, W.L., Brug, J., et al. (2005). Why don't young people volunteer to give blood? An investigation of the correlates of donation intentions among young nondonors. Transfusion, 45(6), 945-955.

McGuire, W.J. (1985). Attitudes and attitude change. In G. Lindzey, \& E. Aronson (Eds.), The handbook of social psychology (Vol. 2, pp. 233-346). New York: Random House.

Mol, M.E., van Boxtel, M.P., Willems, D., \& Jolles, J. (2006). Do subjective memory complaints predict cognitive dysfunction over time? A six-year follow-up of the Maastricht aging study. International Journal of Geriatric Psychiatry, 21(5), 432-441.

Norman, P., \& Conner, M. (2005). The theory of planned behavior and exercise: Evidence for the mediating and moderating roles of planning on intention-behavior relationships. Journal of Sport and Exercise Psychology, 27(4), 488-504.

Ponds, R.W., Commissaris, K.J., \& Jolles, J. (1997). Prevalence and covariates of subjective forgetfulness in a normal population in The Netherlands. International Journal of Aging and Human Development, 45(3), 207-221.

Ponds, W.H.M., \& Jolles, J. (1996). The abridged Dutch metamemory in adulthood (mia) questionaire: Structure and effect of age, sex and education. Psychology and Aging, 11(2), 324-332.

Rasmusson, X., Rebok, G.W., Bylsma, F.W., \& Brandt, J. (1999). Effects of three types of memory training in normal elderly. Aging Neuropsychology and Cognition, 6(1), 56-66.

Schmand, B., Jonker, C., Geerlings, M.I., \& Lindeboom, J. (1997). Subjective memory complaints in the elderly: Depressive symptoms and future dementia. British Journal of Psychiatry, 171, 373-376.

Schmidt, I.W., Dijkstra, H.T., Berg, I.J., \& Deelman, B.G. (1999). Memory training for remembering names in older adults. Clinical Gerontologist, 20(2), 57-73. 
Valentijn, S.A., Hill, R.D., Van Hooren, S.A., Bosma, H., Van Boxtel, M.P., Jolles, J., et al. (2006). Memory selfefficacy predicts memory performance: Results from a 6-year follow-up study. Psychology and Aging, 21(1), $165-172$.
West, R.L., Welch, D.C., \& Yassuda, M.S. (2000). Innovative approaches to memory training for older adults. In R. D. Hill, L. Bäckman, \& A. Stigsdotter Neely (Eds.), Cognitive rehabilitation in old age (pp. 81-105). New York: Oxford University Press. 